\title{
TENDÊNCIAS NO INTERIOR DO PARTIDO OPERÁRIO COMUNISTA (POC)
}

\author{
Karoline Oliveira Brandão \\ Bolsista PROBIC/UEFS, Graduanda em Licenciatura em História, Universidade Estadual de Feira de Santana, \\ membro pesquisadora do LABELU, e-mail: brandaokaro1827@gmail.com \\ Eurelino Teixeira Coelho Neto Orientador \\ Departamento de Ciências Humanas e Filosofia, Universidade Estadual de Feira de Santana, coordenador do \\ LABELU, e-mail: eurecoelho@gmail.com
}

PALAVRAS-CHAVE: Tendências, luta armada, esquerda.

\section{INTRODUÇÃO}

Esta pesquisa trata-se, de forma geral, da caracterização de aspectos da trajetória do Partido Operário Comunista - POC, organização que atuou entre o período de 1968 a fins de 1970 no Brasil. O propósito foi mapear as tendências que surgiram em seu interior, identificar os debates internos que faziam e quais eram os seus conflitos e dilemas acerca, principalmente, do debate da luta armada. O POC, organização que surge em abril de 1968 após realização do seu congresso de fundação, é resultado de uma fusão da antiga Organização Revolucionária Marxista- Política Operária - ORM-PO ${ }^{1}$ (também conhecida como POLOP OU PO) com a Dissidência Leninista do Rio Grande do Sul DL. Essa dissidência começou a se gestar em fins de 1965 e começo de 1966 e neste mesmo ano rompeu com o Partido Comunista Brasileiro - PCB. No seu congresso de fundação, reivindica para si o Programa Socialista para o $\mathrm{Brasil}^{2}$, documento elaborado ainda na fase ORM, aprovado em seu IV Congresso, onde contém as diretrizes centrais e as principais teses da POLOP sobre o desenvolvimento do capitalismo no Brasil, as principais táticas para a organização da classe trabalhadora brasileira por meio do partido revolucionário, na perspectiva da estratégia da revolução socialista, e a análise sobre $o$ foco guerrilheiro.

\section{MATERIAL E MÉTODOS OU METODOLOGIA (ou equivalente)}

A pesquisa se baseou em análise documental da coleção em poder do Laboratório de História e Memória da Esquerda e das Lutas Sociais - LABELU e das fontes digitalizadas disponibilizadas pelo Centro de Documentação e Memória da UNESP CEDEM. Para esta pesquisa, a maioria das fontes analisadas foram de circulação interna do Partido Operário Comunista, em grande maioria disponibilizadas pelo LABELU. Documentos da Organização de Combate Marxista Leninista - Política Operária também

\footnotetext{
1 Organização que surge em 1961, resultando da aproximação de vários pequenos col etivos de marxistas que comungavam de uma rejeição à linha política do Partido Comunista Brasileiro(PCB), por sua opção de aliança com a burguesia nacional e pela estratégia de uma revolução em etapas, vista como reformista. APOLOP trazia como principais defesas a construção do partido revolucionário da classe trabalhadora e o caráter socialista da revolução brasileira.

2 Programa socialista para o Brasil.In: POLOP:Uma trajetória deluta pela Organização independente da classe operária no Brasil. Documentos publicados. Organizadores: Pery Fálcon e Orlando Miranda. Salvador: Centro de Estudos Victor Meyer, 2010.
} 
foram analisados, pois contribuiu com preciosas informações acerca da nossa problemática. Procurou-se analisar os documentos internos com o propósito de identificar os debates e dilemas internos que a organização estava enfrentando, na busca por dar respostas às questões do seu tempo.

\section{RESULTADOS E/OU DISCUSSÃO (ou Análise e discussão dos resultados)}

O debate acerca da luta armada esteve presente no interior do POC por quase toda a sua trajetória. Este foi motivador de diversos embates e fracionamentos entre as fileiras dos seus militantes. Em fins da década 1960 este fracionamento se concretiza sob forma de tendências. Marco Aurélio Garcia quando em 1979 faz um breve balanço da trajetória do partido, escrevendo Uma tentativa chamada Partido Operário Comunista ${ }^{3}$, nos informa que os conflitos internos acerca, principalmente, do debate da luta armada, motivou o surgimento de tais tendências no interior da organização. Antonio Ozaí, em História das Tendências no Brasil traz informações similares, mas identifica dois diferentes momentos em que as tendências se deram. Resultado de debates acirrados e das condições concretas que a clandestinidade e o recrudescimento da repressão estavam impondo, ocorre uma cisão entre as tendências no primeiro momento. $\mathrm{O}$ grupo que se retira do partido se reorganiza e em 1970 reconstitui a Polop, agora chamada Organização de Combate Marxista-Leninista - Política Operária. No segundo momento, após esta cisão, novas tendências se gestam, uma chamada POC-Combate e outra que a esta se opõe.

Grande parte da historiografia do Partido Operário Comunista limita suas análises nos primeiros anos de existência do partido, quando ainda grande parte dos quadros que compunham suas fileiras eram egressos da POLOP, caracterizando-o como continuidade programática e atuante de tal organização. Através do conteúdo trazido por autores como Aarão ${ }^{4}$ e Antonio Ozaí ${ }^{5}$, por exemplo, amplia-se o leque de informações quanto ao que foi o POC. Os autores trazem breves informações sobre algumas questões que motivaram o fracionamento da organização após a década de 1970, posterior à cisão sofrida com os militantes da antiga POLOP, portanto, informando a possível continuidade da sua existência após o ocorrido. Porém, tais informações até então são superficiais, pois não informam com precisão por quanto tempo havia existido o partido. Mas, através da análise de alguns documentos, possível até aqui, constatamos que o POC continuou existindo por quase uma década. $\mathrm{O}$ documento do Andreas Maia, rico em informações sobre um período até então desconhecido da existência do POC, contribuiu para tal descoberta. Portanto, a história do partido não se limita ao primeiro período de existência mais conhecido pela historiografia, que informa até 1970. Até fins desta década o partido continuou "vivo", enfrentando os novos dilemas que o cenário impunha. Mas, este se caracterizou por duas fases. A primeira, por trazer as bases da antiga POLOP e a segunda, quando adotou novos referenciais teóricos e políticos.

Através da análise de alguns documentos podemos começar a caracterizar as principais teses das diferentes frações, na primeira fase, com relação ao grupo que cinde e funda a Organização de Combate Marxista Leninista - Política Operária. O comitê

\footnotetext{
3 Uma tentativa chamada Partido Operário Comunista. Em Tempo, n. 85, 11 a 17 de outubro de 1979

4 REIS FILHO, Daniel Aarão. Classe operária, partido de quadros e revolução socialista. O itinerário da Política Operária-POLOP (1961-1986). In: REIS FILHO, D. A. e FERREIRA, J. Revolução e Democracia. 1964... Rio de Janeiro, Civilização Brasileira, 2007

${ }^{5}$ OZAí, Antonio. História das Tendências no Brasil. Organizações, cisões e propostas. 2ạ ed., São Paulo, Proposta Editorial, [s.d.]
} 
nacional trazia como principais defesas: a construção do partido revolucionário do proletariado como tarefa central, e esta construção se fazia necessário uma coesão política fiel aos princípios básicos do programa socialista; a luta armada como tarefa secundária à formação do partido, pois a tarefa que se colocava era a construção das lutas parciais pela base, nos locais de trabalho, disputando ideologicamente a classe, no intuito de formá-la política e idelogicamente independente dos princípios burgueses e populistas, enfatizando o caráter socialista da revolução; sobre o foco guerrilheiro, este teria que se dar em consonância com a insurreição urbana (sob hegemonia do proletariado); a construção da frente revolucionária como uma das tarefas centrais; a defesa dos Comitês de Empresa; na luta contra o arrocho, em abril de 1968, a defesa era da greve geral como saída para aquele cenário; sobre as eleições gerais, defendiam o voto nulo pela defesa da revolução socialista; e a defesa do princípio leninista do partido e do programa socialista, em contraposição ao que julgavam ser revisionista. A outra tendência, sendo caracterizada sob a ótica do comitê nacional, traz como principais questões: a negação do princípio leninista e rompimento com o centralismo democrático; a pauta da luta armada como imediata para a superação do regime militar e a secundarização das lutas parciais, considerando-as ineficientes para aquele atual estágio da ditadura, de recrudescimento do aparelho repressor do Estado.

Sobre a segunda fase, as informações a que tivemos acesso localizam-se temporalmente a partir de 1971. As duas tendências existentes neste momento são caracterizadas pelo POC-Combate e o grupo que a este se opõe, e ambas aderem à IV Internacional (Internacional Trotskista). A tendência "Combate", como foi chamado aquele primeiro grupo, trazia como principais teses: reivindicação às posições da majoritária da Internacional Trotskista; defendiam a tese que a ditadura só seria vencida por uma "guerra revolucionária" por meio do "exército revolucionário do povo" e as defesas pelas "Uniões Operárias", que foram desenvolvidas pela VAR-Palmares, organização da qual esta tendência se aproximou. A outra tendência trazia como principal defesa, no que se contrapunha incisivamente às primeiras do POC-Combate, o trabalho junto à classe, construindo as lutas parciais, econômicas e democráticas, por meio de um programa de transição. Em decorrência da autocrítica da opção guevarista de luta, feita pela majoritária na IV Internacional, aqui no Brasil as duas tendências do POC se fundem. A partir de então suas defesas políticas passam a privilegiar os comitês de fábrica e comissões de bairro, e as lutas por liberdades democráticas, abandonando quaisquer perspectiva guerrilheira de embate. Supomos que o debate acerca da luta armada não se fez tão presente nos últimos anos de existência da organização. Em 1978 a questão que se colocava, segundo Andreas Maia, era sobre as eleições parlamentares. E, por não conseguir responder aos problemas políticos nacionais e não obter unanimidade de posição referente tais eleições, o partido se dissolve, sem ter "condições de continuar o trabalho por suas próprias forças." São essas as informações que temos sobre essa segunda fase. Não tivemos acesso, até o momento, a nenhum documento que nos ajude a aprofundar essas questões.

\section{CONSIDERAÇÕES FINAIS (ou Conclusão)}

Conseguimos começar a mapear regionalmente as primeiras tendências. O documento Por que nos constituímos em fração nos informa que o fracionamento se deu entre o Comitê Nacional, que se caracterizava como uma tendência, e os grupos das Secretarias regionais do Rio Grande do Sul e São Paulo. Os principais elementos que 
compuseram os debates naquela conjuntura de 1968 à 1970, aproximadamente, se referem a questões referentes aos métodos de luta e às tarefas postas para aquele momento. A precedência da construção do partido revolucionário da classe operária se fez presente a todo momento nas defesas do comitê nacional, se contrapondo a posições que colocavam a urgência da luta armada. Em fins de 1969 essas divergências começaram a se evidenciar no interior do partido caracterizando, assim, o início do fracionamento. O POC-Combate, tendência que surgiu na segunda fase do partido, era constituído por militantes de São Paulo, que se articularam com a VAR-Palmares, pautando a tese das "Uniões Operárias" para o movimento operário e a iminência de uma guerra revolucionária como única alternativa para a derrubada do regime ditatorial. Estas informações foram encontradas nas fontes A história do POC e da LO e Uma tentativa chamada Partido Operário Comunista, e as consideramos como centrais para este primeiro momento da pesquisa. Sobre o debate acerca da luta armada não parecer ter sido central para a organização nos últimos anos de sua existência, é preciso aprofundar na investigação sobre quais eram as questões que estavam sendo postas naquele cenário e quais eram as leituras e prioridades da organização. Quais os dilemas estavam presentes no cenário conjuntural, demandando da organização possivelmente uma nova leitura e posicionamento. Para isto, precisamos ter acesso, para além de outros materiais, dos documentos produzidos por esta tendência, o que não foi possível até o momento. Por fim, o último aspecto que também demandará mais pesquisas se refere a adesão do partido à Internacional Trotskista. Sobre a informação, é preciso pensar os possíveis desdobramentos que motivaram o novo direcionamento e o que realmente isto significa teórico e politicamente. Este é mais um dos elementos que justificam a continuidade desta pesquisa para aprofundar não só esta, mas questões outras.

\section{REFERENCIAS}

BRITO, Tamires Assad Nery de. A GRANDE TAREFA: POLÍTICA OPERÁRIA E A CONSTRUÇÃO DO PARTIDO REVOLUCIONÁRIO (1968-1979). Dissertação de Mestrado em História Social pelo Programa de Pesquisa e Pós-graduação em História da Universidade Estadual de Feira de Santana - UEFS. Feira de Santana, 2016.

COELHO, Eurelino. Dissonâncias à esquerda: a Polop, o golpe e a ditadura militar. IN: MATTOS, Marcelo Badaró, VEJA, Rúben (orgs.) Trabalhadores e ditaduras: Brasil, Espanha e Portugal. 1ª edição. Rio de Janeiro: Consequência, 2014.

MATTOS, Marcelo Badaró. Em busca da revolução socialista: a trajetória da POLOP (1961-1967). IN: REDENTI, Marcelo, REIS FILHO, Daniel Aarão. História do Marxismo no Brasil, vol. V. Campinas, Edunicamp, 2002.

REIS FILHO, Daniel Aarão. Classe operária, partido de quadros e revolução socialista. O itinerário da Política Operária - POLOP (1961-1986). In: REIS FILHO, D. A. e FERREIRA, J. Revolução e Democracia. 1964... Rio de Janeiro, Civilização Brasileira, 2007.

SILVA, Antonio Ozai da. História das tendências no Brasil (Origens, cisões e propostas). $2^{a}$ edição. Dag Gráfica e Editorial: São Paulo. 